solve every other mathematical navigation problem. For self-contained navigation this should surely lead to the use of a great deal more information than is generally available at the moment. (One has in mind the calculation of the greatcircle course and distance after each fix in the ocean, for example.)

Conditions in Jester were much as might be expected in the North Atlantic over a five-week period at that time of year (June, July), but with a larger range of temperatures than usual, During heavy weather in particular the atmosphere down below becomes unusually salt and dank. The computer showed no signs of flagging. A battery change was necessary after 27 days, during which it was used for all navigational calculations.

For general interest a track chart of Jester's voyage showing the noon positions is given at Fig. I.

\title{
English Channel Traffic Control
}

\author{
Ian C. Vendrell \\ (Noratom-Norcontrol)
}

WITH reference to Captain Emden's paper in the April 1975 issue of this Journal, in which he refers to the control and identification of shipping passing through the English Channel, and the numerous articles by Captain Wylie on the subject of computerized shipborne collision avoidance systems, why not adapt the shipborne radar systems for land based control of Channel traffic? A modified shore based system would, with present and predicted traffic movement, be ideally suited to this type of application. As to the problem of operator traffic identification and control, the present civil air traffic control procedures would seem to provide the ideal solution; if all shipping were required to carry dual channel multi-code transponders in addition to the current obligatory navaids.

With a shore based receiver/interrogator system coupled to a computerized collision avoidance system, such as the Databridge, I envisage the system operating as follows. The master, at an internationally agreed range from a particular area, calls the shore station on v.h.f., advises his position and ship's name (call sign) and requests shore station identification and permission to join traffic. On receiving this call the shore based controller would ask the vessel to transmit a selected code on his transponder and by means of a 'light pen' identify the vessel. Once identified the vessel would be tracked as normally seen on shipborne versions of these radar systems. However, once identified, the operator would also insert the target's name/call sign into the system and assign the target an 'ident'. The operator can then recall complete identification of any currently tracked target at will. Proven electronic hardware and computer software is available for such a system, the only requirement to make it a reality being to require all shipping to carry a cheap maritime transponder. I can see no objection from owners to such a small outlay for increased vessel safety through dangerous channels or entry into busy ports.

Rogues would no doubt continue to exist but there are many ways in which the craft dispatched to identify the rogue, be it ship or aircraft, can be presented on the system or PPI, allowing the operator to 'home' it straight on target. 